\title{
¿Qué es la ópera? Una tipología general de ideas filosóficas
}

\section{What is Opera? A General Typology of Philosophical Ideas}

Artículo recibido el 23 de marzo de 2020; devuelto para revisión el 4 de octubre de 2020; aceptado el II de noviembre de 2020; https://doi.org/IO.2220I/iie.I8703062e.202I.II9.2765

Daniel Martín Sáez Universidad de Oviedo, daniel.martins@uam.es, https://orcid. org/00oo-0002-6780-5220

Líneas de investigación Filosofía; musicología; historia de la ópera; historia de la música.

Lines of research Philosophy; musicology; history of opera; history of music.

Publicación más relevante "Estética, musicología y secularización. El mito del nacimiento de la ópera en la historiografía del último siglo", Resonancias 24, núm. 47 (2020): 39-58.

Resumen Desde su nacimiento a finales del siglo XvI, se han escrito muchas teorías sobre la ópera desde una perspectiva histórica, poética, musicológica, estética, política, entre otras. Sin embargo, no ha existido ningún intento sistemático por organizar estas teorías y plantear la pregunta fundamental: ¿qué es la ópera? Se mostrará que el término "ópera” responde a una idea filosófica, que desborda a cualquier disciplina positiva. De hecho, no existe una idea de ópera, sino varias, algunas de ellas contradictorias entre sí. En este artículo presento una tipología de ideas con base en tres criterios lógicos, que he obtenido tras analizar los propios materiales: la distinción sujeto/objeto, la distinción sincrónico/diacrónico y la distinción singular/plural. Esto ya enseña mucho sobre nuestra forma de entender la ópera, pero también nos obliga a preguntarnos si estas ideas son adecuadas para comprender el género.

Palabras clave Filosofía; ópera; tipología; taxonomía; sujeto; objeto.

Abstract Since its birth at the end of the I6th century, many theories have been written about opera from a historical, poetic, musicological, aesthetic, political and other points of view. However, there has been no systematic attempt to organize these theories and to ask the more basic question: what is opera? We will show that the term "opera" responds to a philosophical idea, beyond any positive discipline. In fact, there is no one idea of opera, but several, some of them contradictory to each 
other. In this article we present a typology of ideas attending to three logical criteria, which we have obtained after analyzing the materials themselves: the subject/object distinction, the synchronic/diachronic distinction and the singular/plural distinction. This teaches us a lot about our understanding of opera, but it also forces us to ask ourselves if these ideas are adequate to understand the genre.

Keywords Philosophy; opera; tipology; taxonomy; subject; object. 
DOI: https://doi.org/10.22201/iie.18703062e.2021.119.2765

\author{
DANIEL MARTÍN SÁEZ \\ UNIVERSIDAD DE OVIEDO
}

\title{
¿Qué es la ópera? Una tipología general de ideas filosóficas
}

$\mathrm{D}$ esde que la ópera se empezó a gestar a finales del siglo xvI, se han escrito muchas teorías sobre el género desde una perspectiva histórica, poética, musicológica, teatral, estética, política, etc. Sin embargo, no existe en la bibliografía ningún intento por organizar estas teorías de forma sistemática y plantear la pregunta fundamental: ¿qué es la ópera? En este artículo intentaré mostrar que el término "ópera" responde a una idea filosófica, que desborda a cualquier disciplina positiva y depende de muchas ideas previas, entre las que destacaré como ideas-fundamento, según los criterios que aclararé más adelante, las ideas de objeto, sujeto, sociedad, mundo, obra, espíritu, nación y arte, que a su vez han servido para articular otras muchas ideas.

Este análisis se revela especialmente pertinente tras constatar que no existe una tradición filosófica sistemática en torno a la ópera, sino que más bien nos encontramos ante una pluralidad de ideas genéricas entremezcladas entre sí en diversos autores, que han ido surgiendo a lo largo de cuatro siglos. Mi objetivo es analizar esas ideas desde una perspectiva filosófica, que propongo como punto de partida para una posible filosofía de la ópera. Lo que aquí abordo, por tanto, es el planteamiento de la pregunta por la ópera, empezando por lo que me parece prioritario ordo cognoscendi: la aclaración de la idea por la cual se pregunta.

Para ello, acudiré a la construcción de una tipología de ideas basada en la noción de tipos ideales, entendidos como construcciones teóricas que, guiadas por criterios lógicos y sistemáticos, nos sirven para abstraer del caudal inagotable de ideas "reales" sobre el asunto, mantenidas por diversos autores, una 


\section{DOI: https://doi.org/10.22201/iie.18703062e.2021.119.2765}

366

DANIEL MARTÍN SÁEZ

serie limitada de posiciones "ideales", capaces de acoger la totalidad de respuestas posibles y organizarlas para poder entenderlas, siguiendo para ello criterios lógico-filosóficos lo más precisos posible. ${ }^{\mathrm{I}}$

La dificultad de cualquier clasificación es, precisamente, la elección de esos criterios, que no han de buscarse a priori, sino que han de reconstruirse a partir de los propios materiales. En este caso, tras analizar centenares de textos he obtenido tres criterios, cuya utilidad sólo podrá medirse por sus resultados. El primer criterio de clasificación y el fundamental es la distinción sujeto/objeto, que no por casualidad atraviesa toda la filosofía de la Edad Moderna (e. g., res cogitans/res extensa, Espíritu/Naturaleza, etc.). Aunque era previsible que un género como la ópera, nacido en la Edad Moderna, se ajustase a esta distinción, ha sido la propia clasificación de textos, agrupados según diversos criterios, la que me ha llevado a considerar su centralidad.

A este criterio se suman otros dos: uno temporal (basado en la distinción sincrónico/diacrónico) y otro genérico (basado en la distinción singular/plural), ambos atravesados por la distinción sujeto/objeto. Entre las diversas ideas de ópera, como veremos, algunas enfatizan más un tipo de lógica temporal u otra. El criterio genérico, por su parte, responde a la posibilidad de que la ópera se considere como una entidad singular o plural, lo que permitirá hablar alternativamente de lógicas intraobjetuales e intrasubjetuales, o bien interobjetuales e intersubjetuales.

El entrecruzamiento de estos criterios da como resultado una tabla de ocho posibilidades, que significativamente pueden hacerse corresponder con ocho ideas clave de la filosofía moderna, como se muestra en la figura I, que acaso sirva también para aclarar la lógica dialéctica de tales ideas. Como realidades sincrónicas, según sean singulares o plurales, se pueden entender como objetuales la propia idea de "objeto" (singular) y la idea de "mundo" (entendido, en este caso, como realidad interobjetual, sin negar por ello que existan otras ideas de mundo); como subjetuales se pueden entender las ideas de "sujeto" (singular) y "sociedad" (como realidad intersubjetual). Como realidades diacrónicas, si son objetuales se puede hablar de "obra" (singular) y "arte" (plural), por las razones que luego se verán. Por último, como idea diacrónica intersubjetual se puede entender la idea de "nación", que no se corresponde exactamente con la idea de sociedad. La idea intrasubjetual diacrónica

I. Max Weber, Ensayos sobre metodología sociológica, trad. José Luis Etcheverry (Buenos Aires: Amorrortu, 200I), 85 . 
(que podía haberse ocupado con la idea de Dios), parece haber sido secundaria en la historia de las ideas de ópera, aunque he encontrado algún ejemplo de "espiritualismo". Se trata de un vacío significativo, teniendo en cuenta que el resto de opciones ha recibido algún tipo de respuesta. Esto se debe, sin duda, a la influencia de la teoría de la secularización, por lo general aplicada a la Edad Moderna, que apenas ha dejado espacio a una idea religiosa de ópera, lo cual contrasta con la importancia que la religión ha tenido en la historia de la ópera (entre sus personajes dramáticos, pero también entre sus patrocinadores, etc.) (fig. I).

I. Ocho ideas-fundamento a partir de la distinción sujetolobjeto

\begin{tabular}{lcccc}
\hline & \multicolumn{2}{c}{ Sincrónico } & \multicolumn{2}{c}{ Diacrónico } \\
\cline { 2 - 5 } & Singular & Plural & Singular & Plural \\
\hline Objeto & Objeto & Mundo & Obra & Arte(s) \\
Sujeto & Sujeto & Sociedad & Espíritu & Nación \\
\hline
\end{tabular}

Es importante destacar que esta tabla no pretende encerrar las diversas ideas en compartimentos estancos. En primer lugar, cada idea tiene un carácter dialéctico, que remite negativamente al resto de las ideas organizadas. En segundo lugar, existe entre todas ellas una continua retroalimentación. La clasificación responde, sobre todo, a un criterio de precisión y de prioridad lógica. Por ejemplo, la idea de arte atraviesa todos los apartados en sus diversas formulaciones históricas. Sin embargo, lo más preciso ha sido definirla como presupuesto de disciplinas positivas (la "musicología", "las ciencias del espectáculo", etc.), entendiendo que todas ellas se fundan idealmente en la presuposición de objetos (en plural) estético-históricos, que otorgan una prioridad constitutiva al arte respecto a cualquier otra idea.

Como ya he anticipado, de hecho, esta tabla de ideas-fundamento la he obtenido tras organizar las diversas ideas de ópera en tipos ideales, que a lo largo de la historia se han concretado de formas diversas, lo cual permite delimitar varias subtipologías, que acaso responden a criterios lógico-sistemáticos indeterminados, pero ya marcados por la lógica de la tipología genérica. Además, los propios tipos genéricos podrían haber sido muy diversos en términos históricos, de modo que a continuación hay que precisar la lógica de cada uno de ellos, que requiere apelar a otras ideas. 


\section{DOI: https://doi.org/10.22201/iie.18703062e.2021.119.2765}

368

DANIEL MARTÍN SÁEZ

En primer lugar, las visiones sincrónicas ocupan cuatro tipos ideales básicos: I) la lógica intraobjetual sincrónica deriva en ideas objetuales que denominamos "formalistas", pues están atravesadas por la distinción forma/ contenido, donde predomina la primera parte de la ecuación. Esa lógica intraobjetual puede admitir una o diversas formas entrelazadas (un híbrido de formas que puede ser "armónico" o "caótico", como se verá), y determina la aparición de nuevas subtipologías; 2) al enfoque intrasubjetual sincrónico lo podemos denominar, sin más, "subjetual": en él predominan subtipos que denominaremos "idealistas", "psicologistas", "retóricos" y "vocalistas", todos ellos muy extendidos; 3) la lógica interobjetual sincrónica nos lleva al tipo "ontológico", muy poco desarrollado en la bibliografía, pero con casos importantes e influyentes, como la metafísica de Schopenhauer, y 4) las visiones intersubjetuales sincrónicas dan lugar a "superestructuralismos" de tipo "sociologista" y "politologista", a los que sumaremos un subtipo "republicano".

Las visiones diacrónicas existentes se pueden resumir en otros cuatro tipos: 5) la lógica intraobjetual diacrónica recibirá el nombre de "romántica", al interpretar la ópera como un tipo específico de "obra" que remite a una historia pasada o futura. A ella corresponden los enfoques "nostálgicos", que entienden la ópera como la reaparición (exitosa o fracasada) de la tragedia griega, pero también la idea wagneriana que denomino "alquímica", pues presenta sus "dramas" (en contraposición a la "ópera” como un objeto híbrido) como una verdadera fusión de artes; 6) las visiones interobjetuales diacrónicas, fundamento de ciertas disciplinas universitarias, merecerán el apelativo de "gremiales", al suponer la existencia de objetos artístico-históricos demarcables desde categorías estéticas como "música", "literatura" o "espectáculo" (a veces combinadas en ejercicios "interdisciplinares"), sin las cuales esas disciplinas carecerían de sentido filosófico; 7) el enfoque intrasubjetual diacrónico lo definiré como "espiritualismo", poniendo un ejemplo "vitalista" y otro "metafísico", consistente en tomar la ópera como expresión máxima de "la vida", los "mundos suprasensibles", etc., y 8) las ideas de tipo intersubjetual en sentido diacrónico han dado lugar a "localismos", al definir a la ópera desde ideas nacionales, ya sean "particularistas" o "populistas" (fig. 2).

Cada uno de estos tipos implica, como es obvio, un reduccionismo, pero los tipos ideales no aspiran a clasificar los materiales textuales ad hoc en un tipo fijo. Más bien, se trata de acudir a los tipos para organizar los materiales, dado que la mayoría de los autores suele utilizar planteamientos muy similares, aunque supongan la combinación de diversos tipos ideales. Como he anticipado, 
DOI: https://doi.org/10.22201/iie.18703062e.2021.119.2765

¿QUÉ ES LA ÓPERA? UNA TIPOLOGÍA GENERAL

2. Organización de las tipologías a través de los criterios antedichos

\begin{tabular}{lcccc}
\hline & \multicolumn{2}{c}{ Sincrónico } & \multicolumn{2}{c}{ Diacrónico } \\
\cline { 2 - 5 } & Singular & Plural & Singular & Plural \\
\hline Objeto & Formalismos & Ontologismos & Romanticismos & Gremialismos \\
Sujeto & Subjetualismos & Superestructuralismos & Espiritualismos & Localismos \\
\hline
\end{tabular}

Wagner acude a dos tipos para distinguir "ópera” y "drama”, y aun dentro de cada tipo emplea ideas peculiares. La utilización de más tipos, sin embargo, no muestra necesariamente la profundidad de un autor. En muchos casos, denota su imprecisión, al depender de distinciones que de manera eventual podremos considerar metafísicas, como sujeto/objeto, forma/contenido, etcétera.

A continuación, explicaré y pondré algunos ejemplos de cada una de estas ideas de ópera, organizadas en los siguientes tipos y subtipos ideales:

LÓGICA SINCRÓNICA

I. Tipos formalistas
a. Esencialista
b. Híbrido-armónico
c. Híbrido-caótico
d. Temático

2. Tipos subjetuales
a. Idealista
b. Psicologista
c. Retórico
d. Vocalista

3. Tipos ontológicos
a. Inauténtico

4. Tipos superestructurales
a. Sociológico
b. Politológico
c. Republicano

LÓGICA DIACRÓNICA

\section{Tipos románticos}
a. Nostálgico-positivo
b. Nostálgico-negativo
c. Alquímico

6. Tipos gremiales
a. Musicológico
b. Literario/dramático
c. Espectacular
d. "Opera Studies"

7. Tipos espiritualistas
a. Vitalista
b. Metafísico

8. Tipos localistas
a. Particularista
b. Populista 


\section{DOI: https://doi.org/10.22201/iie.18703062e.2021.119.2765}

370

DANIEL MARTÍN SÁEZ

La pluralidad de enfoques dentro de cada tipo, sobre los que se extienden los ejemplos en los últimos cuatro siglos, es una muestra del interés que ha despertado la ópera en los más variados ámbitos, lo que ya nos dice mucho acerca de su compleja realidad histórica. Sobre cada uno de ellos existen innúmeros ejemplos, desarrollados por autores muy influyentes, desde músicos, dramaturgos, directores de escena y literatos hasta filósofos, sociólogos, musicólogos e historiadores del teatro.

Para evitar toda acusación de apriorismo y para mostrar que esta tipología no es una cama de Procusto, limitaré mi análisis a las ideas que sus autores enuncian de forma explícita, lo cual significa que esta tipología no agota las ideas posibles en el presente. Los musicólogos e historiadores del teatro de los últimos cien años, por ejemplo, han desarrollado en ejercicio una idea de ópera más compleja, pero incluso en este caso la clasificación es interesante, pues esos mismos musicólogos, cuando se entregan de forma espontánea a definir la ópera, recaen en los tipos ideales más ingenuos. Además, todos ellos nos ayudan de algún modo a comprender la realidad compleja de la ópera, que sin duda ha moldeado nuestra manera de entender las formas artísticas, nuestras ideas acerca del sujeto, sus pasiones y afectos, el cosmos y la divinidad, nuestra idea de la política y las relaciones sociales, así como su conexión con otros géneros del pasado, como la tragedia griega y los grandes géneros musicales, literarios y dramatúrgicos a los que han contribuido las distintas naciones europeas.

\section{Las ideas formalistas de ópera}

Llamamos visiones "formalistas" a aquellas que definen la ópera, de modo sincrónico, como un "objeto" de contornos definibles, según la distinción sujeto/objeto, atravesada por la distinción forma/contenido. Lo esencial de ese objeto sería su "forma", a la que se subordinarían sus "contenidos". La necesidad de la historiografía por tratar con artefactos "textuales" y "compositivos", dejando de lado (sin salir de esa lógica sincrónica) factores subjetuales como puedan ser los cantantes, los elementos performativos o el público, es denunciada a menudo por los musicólogos como una tendencia generalizada, ${ }^{2}$

2. "Muchos estudiosos tienen problemas con los cantantes. Al menos hasta hace poco, hemos preferido estudiar obras, no sus interpretaciones, y las obras se fijan en textos tanto verbales (libretos) como musicales (partituras). Por ejemplo, analizar el tratamiento de los Leitmotiv en el El anillo de Wagner, o el manejo de técnicas seriales en Lulú de Berg, sitúa nuestra atención en la página impresa y en el proceso compositivo, lo cual deriva en la consiguiente 


\section{DOI: https://doi.org/10.22201/iie.18703062e.2021.119.2765}

¿QUÉ ES LA ÓPERA? UNA TIPOLOGÍA GENERAL

marcada en gran medida por nuestra idea de arte como repertorio de "objetos de museo". ${ }^{3}$

Cuando se define la ópera como una forma simple y continua, podemos hablar de un formalismo "esencialista", como el que encontramos en la casi totalidad de los diccionarios de uso común y de musicología, como la Guía Akal de la Música de Stanley Sadie, ${ }^{4}$ el Diccionario enciclopédico de la música de Alison Latham $^{5}$ o The Concise Oxford Dictionary of Opera de John Warrack y Ewan West. ${ }^{6}$ Baste como ejemplo el Diccionario Harvard de Música de Don Michael Randel:

Un drama que es fundamentalmente cantado, acompańado por instrumentos y presentado teatralmente. El hecho de que la ópera sea sobre todo cantada la distingue de obras dramáticas en las que la música es incidental o claramente

devaluación de las contingencias performativas. Por eso tendemos a preocuparnos más, digamos, por el simbolismo musical del Orfeo de Monteverdi, que por lo que costó llevar esa obra al escenario" ("Many scholars also have problems with singers. At least until recently, we have preferred to study works, not their performances, and works are fixed in texts both verbal [librettos] and musical [scores]. For example, analyzing the treatment of leitmotifs in Wagner's Ring, or the handling of serial techniques in Berg's Lulu, focuses the attention on the printed page, and on compositional process, which therefore forces a consequent downplaying of performative contigencies. Thus, we have tended to worry more about, say, Monteverdi's musical symbolism in Orfeo than what it took to get that work on the stage"), en Tim Carter, "What is Opera", en Helen M. Greenwald, ed., The Oxford Handbook of Opera (Nueva York: Oxford University Press, 20I4), I6. Todas las traducciones son mías, salvo que se indique expresamente lo contrario.

3. Véase Lydia Goehr, The Imaginary Museum of Musical Works: An Essay in the Philosophy of Music (Oxford: Clarendon Press, 1992).

4. "Una ópera es un drama puesto en música, para ser representado con acompañamiento orquestal. Puede ser completamente cantado o puede haber secciones de diálogo hablado", en Stanley Sadie y Alison Latham, Guía Akal de la música (Madrid: Akal, 2009), 82.

5. "Una definición razonable que distingue a la ópera de los demás géneros es la de una obra escénica con acompañamiento instrumental en la que el canto es el vehículo principal para retratar la acción dramática y las emociones de los personajes", en Alison Latham, Diccionario enciclopédico de la música (Ciudad de México: Fondo de Cultura Económica, 20I4), I086.

6. "Ópera (italiano: "obra”; una abreviación de opera in musica). Un drama cantado con acompañamiento instrumental con uno o más cantantes con vestuario; * diálogo recitado o hablado puede separar los números musicales". (“Opera [It.: "work"; an abbreviation of opera in musica]. A drama to be sung with instrumental accompaniment by one or more singers in costume; * recitative or spoken dialogue may separate musical numbers"), en John Warrack y Ewan West, The Concise Oxford Dictionary of Opera (Oxford y Nueva York: Oxford University Press, 1996), 374. 


\section{DOI: https://doi.org/10.22201/iie.18703062e.2021.119.2765}

372

DANIEL MARTÍN SÁEZ

subsidiaria respecto al drama. El hecho de que se presente teatralmente la distingue del oratorio. ${ }^{7}$

La idea de esta esencia formal tiene muchas consecuencias, como la inclusión de la ópera como parte de otros géneros, no en virtud de conexiones históricas, sino como resultado de análisis formales comparativos, como hace John D. Drummond en Opera in Perspective, para quien existen "varias formas de drama-musical humano", de modo que "la opera es, estrictamente hablando, un hijo particular en la familia del drama-musical", que tendría "algunas características básicas en común, y otras que reflejan las culturas de las que es parte". ${ }^{8}$

Algo más complejas son las visiones "híbridas", que comprenden la ópera como un conjunto de formas diversas, las cuales podrían armonizar o discordar entre sí. Por su concisión, merece la pena citar la definición de Michael Halliwell en Opera and the Novel:

La ópera es una forma híbrida de arte con una historia de perpetua tensión entre las demandas del texto y las de la música, por no mencionar las demandas realizadas por otros géneros como la danza, así como factores tales como el diseño escénico y otros oficios teatrales involucrados. Este conflicto fundamental entre las palabras y la música es tan viejo como la ópera misma y, de hecho, ha sido el tema autorreflexivo de bastantes óperas. ${ }^{9}$

Como ejemplo de tesis armónica puede citarse The Opera. Past and Present de William Foster Apthorp, cuando sostiene que "la esencia de la ópera" sería la "unión 'química" de tres artes, lo que denomina un "trébol de artes". Esta capacidad para unir diversas formas sería, en este caso, lo que vincula la ópera con otros géneros, considerados del mismo modo. Apthorp remonta los intentos

7. Don Michael Randel, Diccionario Harvard de Música, ed. de Luis Carlos Gago (Madrid: Alianza, 1997), 725 .

8. John D. Drummond, Opera in Perspective (Mineápolis: University of Minnesota Press, I980), I3.

9. "Opera is a hybrid art form with a history of perpetual tension between the demands of the text and those of the music, not to mention the demands made by other genres such as dance, as well as factors such as scenic design and other allied theatre crafts. This fundamental conflict between words and music is as old as opera itself and has, in fact, been the self-reflexive subject of several operas". Michel Halliwell, Opera and the Novel. The Case of Henry James (Ámsterdam y Nueva York: Rodopi, 2005), 2. 
de hacer ópera a los egipcios y los asirios, aunque sólo los griegos parecerían haberlo conseguido, en cuyo caso ellos merecerían la prioridad como padres de la ópera: "Es evidente que la ópera no puede aparecer hasta darse tal unión o, suponiendo que ello hubiera existido en el viejo drama griego, reestablecerse." ${ }^{\text {Io }}$ Lo mismo sostiene Francisco Asenjo Barbieri cuando se refiere al drama de Elche como "verdadera ópera religiosa". ${ }^{\text {II }}$

Otros ejemplos de este tipo de formalismo se pueden encontrar desde Esteban de Arteaga, ${ }^{\text {I2 }}$ uno de los primeros historiadores de la ópera, hasta Stanley Sadie, ${ }^{13}$ aunque no siempre lleven este formalismo, como Apthorp o Barbieri, a sus últimas consecuencias filosóficas. La influencia de esta postura es enorme en muchas instituciones académicas del presente, como prueba la consolidación en China, en Estados Unidos y en Europa del sintagma "ópera china". Muchos investigadores lo utilizan para referirse a un conjunto de géneros (el denominado xiqŭ, en pinyin) que nada tienen que ver con la ópera, como también ha ocurrido con el kabuki y el nō, ambos denominados a veces "ópera japonesa", o incluso con el nautanki de la India. ${ }^{14}$

Esto mismo es aplicable a quienes consideran esa hibridación como imposible, al entender la ópera como un objeto "híbrido-caótico". Esta postura es la más común cuando se quiere atacar la ópera, como ejemplifica bien la famosa chanza de Samuel Johnson: "Ópera italiana, un entretenimiento exótico e irracional que siempre ha sido combatido y siempre ha prevalecido." Is Las formas artísticas serían tan distintas entre sí que carecería de todo sentido

Io. William Foster Apthorp, The Opera. Past and Present. An Historical Sketch (Nueva York: Charles Scribner's Sons, I90I), 3.

II. Francisco Asenjo Barbieri, 2. Escritos, Emilio Casares Rodicio, ed. (Madrid: ICCMU, 1994), 377 .

I2. Esteban de Arteaga, Le rivoluzioni del Teatro musicale italiano dalla sua origine fino al presente (Venecia: Carlo Palese, I785), I-2.

13. Stanley Sadie, ed., History of Opera (Londres: MacMillan, 1990), I.

I4. Esta idea fue defendida por el autor en el XXIV World Congress of Philosophy (CwP 20I8), organizado por la International Federation of Philosophical Societies (FISP) y la Universidad de Pekín, China, del 13 al 20 de agosto de 2018, en el China National Convention Center (CNCC), con la ponencia titulada "Western Opera and Chinese Opera: A Philosophical Problem". Véase Dolores Menstell Hsu, "Musical Elements of Chinese Opera", The Musical Quarterly 50, núm. 4 (1964): 443. Dado que la definición no incluye el tipo de actores, incluso podríamos incluir géneros como el bunraku de Japón.

I5. Samuel Johnson, Lives of the English Poets, vol. II (Londres: C. Bathurst et al., I78I), 499. 


\section{DOI: https://doi.org/10.22201/iie.18703062e.2021.119.2765}

374

DANIEL MARTÍN SÁEZ

unirlas. Un ejemplo prototípico aparece en Sur les opera (publicada en 1684) de Saint-Évremond:

Si queréis saber lo que es una ópera, os diré que es un trabajo bizarro de poesía y música, en el que el poeta y el músico se estorban mutuamente, esforzándose en hacer una obra desordenada. ${ }^{16}$

El teatro a la moda (1720) de Benedetto Marcelo llevará esta idea a su extremo satírico, que en muchos casos se traduce en un recelo ante formas artísticas extrańas a la propia nación, como ocurre en Comparaison de la musique italienne et de la musique française (I704) de Lecerf de la Vieville. ${ }^{17}$ Richard Wagner acude a una idea parecida en Ópera y drama (I852), donde parte de una tergiversación del nacimiento de la ópera, un género que "no ha nacido del pueblo, sino del arbitrio histórico", creado por un grupo de cortesanos que sólo podían ofrecer a sus soberanos un "género artístico enteramente lleno de contradicciones y antinatural”, justamente porque habría invertido la relación forma/contenido, que acaba identificando con la distinción música/drama. La ópera tomó la forma (la música) como fin, cuando el verdadero fin debería ser el contenido (el drama), convertido en un medio. Toda la historia de la ópera, según Wagner, puede interpretarse como un fracaso, desde Metastasio (que "no causó el menor estorbo al músico") hasta Meyerbeer (cuya música se define como "un efecto sin causa"), pasando por Gluck, Mozart y Rossini. ${ }^{18}$ Wagner propone modificar la unión de música y literatura dando prioridad al drama, un término opuesto a ópera, como se verá en las tipologías románticas.

Muchos autores, haciendo de la necesidad virtud, han convertido esa tensión de formas en una ventaja. Es el caso de autores como Joseph Wechsberg, que incluso duda si considerar "arte" a la ópera, dada su combinación de formas; $;^{19}$ Oskar Bie, para quien las contradicciones de la ópera son una ventaja

I6. 'Si vous voulez savoir ce que c'est qu'un Opera, je vous diray que c'est un travail bizarre de Poësie, de Musique, où le Poëte \& le Musicien égalment géhennez l'un par l'autre, se donnent bien de la peine à faire un meschant ouvrage", en Saint-Évremond, "Sur les opera, a Monsieur de Bouquinquant”, en Oeuvres meslées, XI (París: Claude Barbin, I684), 90-9I.

17. Benedetto Marcello, Teatro a la moda (Madrid: Anaya, 20II); Lecerf de la Vieville, Comparaison de la musique italienne et de la musique française, en Laura Naudeix, La Première Querelle de la musique italienne (París: Garnier, 2018).

I8. Richard Wagner, Ópera y drama (Madrid: Akal, 2013), 70-ı18.

19. El autor se refiere a la ópera como "la forma de arte más controvertida; de hecho, no hay 
para comprehender la complejidad de la realidad ${ }^{20}$ o Herbert Lindenberger, cuya Opera. The Extravagant Art (1984) parte de "una noción de ópera como una forma elevada y extravagante", marcada por un hipotético "conflicto inherente entre palabra y música". ${ }^{21}$

Lindenberger nos sirve para dar pie al enfoque formal "temático", que suele estar vinculado al enfoque híbrido-caótico en su versión positiva, y que en el fondo deriva en un enfoque metafísico, que convierte la ópera en una realidad espiritual suprema. Cuando el caos objetual de la ópera se entiende de forma positiva, comúnmente se apela a los contenidos que resultarían apropiados a ese caos formal. Así cobra interés otra famosa chanza de George Bernard Shaw, cuando ante la pregunta "¿qué es la ópera?" respondió así: "un tenor y una soprano quieren hacer el amor, pero el barítono se lo impide". ${ }^{22}$ En Les Beaux arts reduits à un même principe (I746), Charles Batteux se refiere a la ópera como un género destinado a lo "maravilloso", precisamente a causa de sus formas, ${ }^{23} \mathrm{y}$ algo parecido ocurre en las Lecciones sobre la estética de Hegel según la versión de Heinrich Gustav Hotho:

un completo acuerdo sobre si debe ser considerada un arte en absoluto" ("The most controversial art form. In fact, there is no complete agreement on whether it should be considered an art at all”), en Joseph Wechsberg, The Opera (Londres: Weidenfeld and Nicolson, 1972), 2I.

20. Oscar Bie, Historia Universal de la Ópera, trad. Santiago Sánchez Calvete (Buenos Aires: Centurión, I947[1913]). Para Bie la ópera es "difícil", "paradójica hasta la locura", un género donde "se estrella la lógica", "una cortesana", "un enigma del arte especulativo", "el arte de las contradicciones", pero es también por ello "el único arte que influye toda la vida", "el arte más diverso, pletórico de referencias y empapado de los pensamientos y sentimientos que se acumularon durante décadas", "una enseñanza personificada de todo lo estético", precisamente porque aúna "artes contradictorias para ponerlas a prueba en sus últimas excitaciones" (9-I2).

2I. Herbert Lindenberger, Opera. The Extravagant Art (Ithaca y Londres: Cornell University Press, 1984), 20.

22. Citado en Martha Feldman, Opera and Sovereignty (Chicago y Londres: The University of Chicago Press, 20I0), 386.

23. "También puede haber dos clases de Tragedia, una heroica, que se llama simplemente Tragedia: la otra, maravillosa, que se ha llamado Espectáculo Lírico u Ópera. Lo maravilloso se excluye del primer tipo, pues estamos ante hombres actuando como hombres; mientras que, en el segundo, los Dioses actúan como Dioses, con todo el aparato de un poder sobrenatural; lo que no fuera maravilloso, dejaría de ser en cierto modo plausible. Estas dos especies tienen reglas en común, y si tienen alguna particular, es sólo en relación con la condición de los actores o con la elección de los temas donde hay alguna diferencia. / Una Ópera es, pues, la representación de una acción maravillosa. Es lo divino de la epopeya puesto en escena". ("Il peut y avoir aussi deux espèces de Tragédie, l'une heroïque, qu'on appelle simplement 


\section{DOI: https://doi.org/10.22201/iie.18703062e.2021.119.2765}

376
DANIEL MARTÍN SÁEZ

Particularmente la ópera quiere y debe mantenerse en un limitado círculo de ellos [de temas], y una y otra vez oímos las quejas y alegrías, la desventura y la ventura amorosas, la fama, el honor, el heroísmo, la amistad, el amor materno, el amor filial, conyugal, etcétera. ${ }^{24}$

Este enfoque aspiraría a explicar por qué los temas característicos de la ópera giran casi siempre en torno al amor y la muerte, ${ }^{25}$ aunque la idea por excelencia de los formalismos es lo "inverosímil", como muestran no sólo sus defensores ${ }^{26}$ sino también sus detractores. ${ }^{27}$ Esa inverosimilitud suele ser achacada a la música, que se considera incapaz de expresar cualquier contenido "realista".

Tragédie: l'autre merveilleuse, qu'on a nommée Spectacle Lyrique ou Opera. Le merveilleux est exclus de la premiere espèce, parce que ce font des hommes qui agissent en hommes; au lieu que dans la seconde, les Dieux agissant en Dieux, avec tout l'appareil d'une puissance surnaturelle; ce qui ne seroit point merveilleux, cesseroit en quelque sorte d'être vraisemblable. Ces deux espèces ont leurs régles communes: \& si elles en ont de particulieres; ce n'est que par rapport à la condition des Acteurs ou au choix des matieres où il y quelque différence. I Un Opera est donc la représentation d'une action merveilleuse. C'est le divin de l'Epopée mis en spectacle"), en Charles Batteux, Les Beaux arts reduits a un même principe (París: Durand, I746), 2II. Esta idea de la ópera como representación de una acción maravillosa es esencial, aunque sólo sea porque aparecerá en la Enciclopedia de Diderot y D’Alambert, así como en Lefranc de Pompignan.

24. George W. F. Hegel, Lecciones sobre la estética, trad. Alfredo Brotons Muñoz (Madrid: Akal, I989 [I834]), I7I.

25. "La muerte es un tema tan probable como improbable para un libro de ópera. Los cuatrocientos ańos de historia de esta forma de arte han demostrado que los compositores y libretistas buscan temas poderosos que hablen a su público, y parece que pocos temas hablen tan alto y con tanta fuerza como el amor y la muerte". ("Death is both a likely and an unlikely theme for a book about opera. The four-hundred-year-old history of this art form has demonstrated that composers and librettists look for powerful subjects that speak to their audiences, and it would seem that few subjects speak as loudly or powerfully as love and death"), en Linda Hutcheon y Michael Hutcheon, Opera. The Art of Dying (Cambridge y Londres: Harvard University Press, 2004), I.

26. La idea incluso aparece en Alberto Basso, ed., Musica in scena. Storia dello spettacolo musicale, vol. I (Turín: Unione Tipografico-Editrice Torinese, I995), XIII, que define la ópera como "la expresión más sorprendente de lo inverosímil, la tarea de acelerar el curso de las emociones provocadas por las situaciones escénicas y de dilatar y potenciar su efecto". ("L'espressione più sorprendente dell'inverosimile, il compito di accelerare il corso delle emozioni provocate dalle situazioni sceniche e di dilatarne e potenziarne l'effetto").

27. Así se opone a ella Raimondo Boucheron, Filosofia della musica o Estetica applicata a questarte (Milán: Giovanni Ricordi, I842), 5I: "Resulta increíble que hombres educados en la belleza de las artes hayan confundido el canto de la mujer que acuna a su hijo para dormirlo, y 


\section{DOI: https://doi.org/10.22201/iie.18703062e.2021.119.2765}

¿QUÉ ES LA ÓPERA? UNA TIPOLOGÍA GENERAL

\section{Las ideas subjetuales de ópera}

Las ideas subjetuales, también atravesadas por la distinción sujeto/objeto, son más variadas que las objetuales, dada la necesidad de apelar al segundo término de la ecuación. El enfoque "idealista" supone que las óperas son la materialización de la "idea" de un genio creador. El propio nacimiento de la ópera se ha interpretado a menudo como la materialización de la "idea" de un grupo de académicos, según la distinción idealista teoría/práctica, como en parte ya hemos visto en Wagner. Pero hay dos compositores que han recibido mayor atención en la bibliografía desde este enfoque: Claudio Monteverdi y el propio Richard Wagner. El ejemplo más obvio en torno a la primera figura es Monteverdi. Creator of Modern Music (1950) de Leo Schrade, quien llega a afirmar que "el drama musical fue creado por Monteverdi solo, sin ningún precursor real", y quita toda importancia a las óperas previas. ${ }^{28}$

Se pueden encontrar otros muchos ejemplos de este "mito monteverdiano" desde Ansaldo Cotta ${ }^{29}$ hasta Mauro Calcagno, ${ }^{30}$ pero los ejemplos más clara-

del artesano que aligera el trabajo cotidiano, con el canto dramático, encontrando absurdo que se muera cantando, es decir, expresando los últimos acentos con la propia lengua, mientras que no se encuentra absurdo que estos acentos sean en verso. Es necesario haber escuchado a Lalande, Pasta, Malibran, Morandi, y Lablache, y Tamburini, y Donzelli, y Rubini, y Tacchinardi, y Filippo Galli en L’Agnese, en La Gazza Ladra, en Otello, en Giulietta e Romeo, en Il Pirata, en La Straniera, en Norma, para convencerse de la verdad que puede asumir el canto dramático, y cómo incluso desaparece la idea de artificio cuando el arte ha alcanzado ese grado supremo de sentimiento". ("Fa stupore che uomini educati al bello delle arti abbiano confuso il canto della donnicciuola che sta cullando il bimbo per addormentarlo, e dell'artiero che fa più lieve il diuturno faticare, col canto drammatico, trovando assurdo che vi si muoja cantando, cioè esprimendo con un linguaggio proprio gli ultimi accenti, mentre poi non si trova assurdo che questi accenti siano in versi. Conviene avere sentito la Lalande, la Pasta, la Malibran, la Morandi, e Lablache, e Tamburini, e Donzelli, e Rubini, e Tacchinardi, e Filippo Galli nell' Agnese, nella Gazza Ladra, nell'Otello, nella Giulietta e Romeo, nel Pirata, nella Straniera, nella Norma, per convincersi della verità che può assumere il canto drammatico, e come sparisca persino l'idea d'artifizio quando l'arte ha raggiunto quel sommo grado di sentimento").

28. "By Monteverdi alone, without any real precursor", en Leo Schrade, Monteverdi. Creator of Modern Music (Londres: Victor Gollancz LDT, 1979), 226.

29. Véase Paolo Fabbri, Monteverdi, trad. Carlos Alonso (Madrid: Turner, 1989), 478.

30. Véase Mauro Calcagno (From Madrigal to Opera [Berkeley y Los Ángeles: University of California Press, 20I2], I8-24), para quien ópera sería la materialización de la idea moderna de sujeto, que se podría remontar al petrarquismo, entendido como un "paradigma cultural" que habría determinado desde entonces la cultura europea. El lugar idóneo para entender qué sea la ópera no sería ya Monteverdi, sino una obra concreta de Monteverdi: Orfeo. Calcagno 


\section{DOI: https://doi.org/10.22201/iie.18703062e.2021.119.2765}

378

DANIEL MARTÍN SÁEZ

mente idealistas giran en torno a Wagner, empezando por "Richard Wagner en Bayreuth" de Friedrich Nietzsche, que se refiere así a la creación del teatro wagneriano:

Que un individuo en el transcurso de una vida humana ordinaria pueda presentar algo radicalmente nuevo, eso puede irritar, en efecto, a todos aquellos que tienen una confianza ciega en el carácter paulatino de toda evolución, como si esa parsimonia fuese una especie de ley moral: ellos mismos son lentos y exigen lentitud - y he aquí que ahora ven a alguien muy veloz, no se explican cómo lo consigue y acaban siendo malignos con él. De una empresa de las características de Bayreuth no había ningún tipo de síntomas precursores, ni hubo transiciones ni tampoco mediaciones de ninguna clase; el largo camino que conducía a la meta, así como la meta misma, no los conocía nadie, excepto Wagner. Ha sido esta empresa la primera circunnavegación en el campo del arte: en la cual, por lo que parece, se descubrió no sólo un arte nuevo, sino el arte mismo. ${ }^{3 \mathrm{~T}}$

Como consecuencia de esta sintonía entre ambos, la cadena Monteverdi-Wagner se repite a menudo en la bibliografía. Un ejemplo radical es Rafael Mitjana, cuando atribuye a Monteverdi la tarea de "reivindicar los derechos de los sentidos y de la música libre, únicamente sujeta a los impulsos de su corazón de hombre superior", ${ }^{22}$ y afirma después que "obedeciendo tan sólo a los movimientos pasionales, Wagner, lo mismo que Monteverde, hace su revolución". 33

Esta postura linda con el enfoque "psicológico", que no pone tanto el acento en lo producido a través de la idea, como en su productor, ya sea como individuo o como paradigma del colectivo. En un caso extremo, la ópera nos situaría

comienza su libro con una cita de Adorno: "Toda ópera es Orfeo", y termina con otra cita del filósofo alemán, según la cual Orfeo sería "la primera ópera auténtica" (I-I4 y 42). La ópera misma, entendida aquí como plasmación de ese primer analogado petrarquiano, sería una idea de subjetividad. La única virtud de este enfoque es que le permite interpretar al protagonista de la ópera como una subjetualidad concreta. En Orfeo de I607, éste sería el príncipe de Mantua, Francesco Gonzaga.

3I. Friedrich Nietzsche, "Richard Wagner en Bayreuth", Escritos sobre Wagner, Joan B. Llinares, ed. (Madrid: Biblioteca Nueva, 2003), 88.

32. Rafael Mitjana, Claudio Monteverde (1567-1643) y los origenes de la ópera italiana. Conferencia leida en el Centro de Estudios Estéticos de Uppsala el 7 de diciembre de Igoo (Málaga: Establecimiento Tipográfico "La Moderna", I91I), I5.

33. Mitjana, Claudio Monteverde, 2I. 
ante el psiquismo como tal, casi como una psique que, desde sí misma, contiene al resto de psiquismos, o incluso (en virtud de algún tipo de panpsiquismo más o menos reconocido) elementos externos al psiquismo, pero sólo abordables desde éste. En el ensayo de Robert Donington, Opera and its Symbols (1990), la ópera nos conduce — por medio de la escucha - al universo del "inconsciente", ${ }^{34}$ como también ocurre en El espiritu de la ópera. La exaltación de las pasiones humanas de Marie-France Castarède, basado en la idea de que "mucho antes de amar a la persona de la madre, el bebé ama a la voz materna" ${ }^{35}$ de modo que la ópera nos retrotraería a esa conexión originaria. La autora incluso acepta la ingenua idea de Roland Barthes en L'obvie et l'obtus, que identifica los registros vocales con las figuras familiares:

En nuestra sociedad occidental, a través de los cuatro registros vocales de la ópera, es Edipo quien triunfa: toda la familia está ahí, padre, madre, hija e hijo, simbólicamente proyectados — sean cuales fueren los avatares del argumento y las alternancias de los roles - en el bajo, la contralto, la soprano y el tenor. ${ }^{36}$

Una idea similar ha sido mantenida por Susan Rutherford (20I2), que apela a las "relaciones paternofiliales" construidas "por medio de la 'musicalidad comunicativa' no verbal de una interacción vocal mutua", ${ }^{37}$ análoga a la impostación de la voz típica de cierto repertorio, lo que explicaría nuestro placer auditivo..$^{38}$

34. "Casi tan inmediata como los sueños, y mucho más coherente, la ópera ofrece un camino real al inconsciente, recurriendo a regiones de la psique en las que la conciencia tiene poco poder de penetración", ("Almost as immediately as dreams, and fare more coherently, opera offers a royal road into the unconscious, drawing as it does on regions of the psyche where consciousness has little power to penetrate"), en Robert Donington, Opera and its Symbols. The Unity of Words, Music, and Staging (New Haven y Londres: Yale University, 1990), 3.

35. Marie-France Castarède, El espiritu de la ópera. La exaltación de las pasiones humanas, trad. Julià de Jòdar (Barcelona: Paidós, 2003), I8.

36. La autora deduce de ahí que "lo propio de la ópera es ofrecer al inconsciente de cada oyente un espejo (con mayor o menor fuerza reflectante, según el genio del compositor) de sus fantasmas originarios: fantasmas del nacimiento y dela muerte, dela escena primitiva, dela diferencia de los sexos, de la seducción, de la castración. Todos estos enigmas han exigido, en el imaginario del compositor, respuestas que éste nos entrega a través de una historia ofrendada a nuestra fantasmagoría personal. De esta suerte, el oyente espectador es invitado a una regresión onírica" (Castarède, El espiritu de la ópera, 23).

37. Susan Rutherford, "Voices and Singers", Cambridge Companion to Opera Studies, Nicholas Till, ed. (Cambridge: Cambridge University Press, 20I2), II7.

38. "Nuestro placer por la fragmentación melismática de la ópera o la oclusión de la palabra 


\section{DOI: https://doi.org/10.22201/iie.18703062e.2021.119.2765}

380

DANIEL MARTÍN SÁEZ

Otro enfoque subjetualista común en la literatura es el "retórico". Lo esencial de la ópera no sería su poder para imbuirnos en un psiquismo individual o genérico, sino su capacidad para despertar o mover determinadas emociones, ideas o afectos, en virtud de una serie de cualidades retóricas. Jean de La Bruyère, por ejemplo, afirma que lo propio de la ópera consistiría en mantener "los espíritus, los ojos y las orejas bajo un mismo encantamiento". ${ }^{39}$ Esta unión de sentidos es un análogo perfecto de la unión de artes de las visiones híbridas. Este enfoque es frecuente desde los orígenes de la ópera, pero resulta especialmente común a partir de mediados del siglo XVII, cuando se extienden las ideas publicadas en Les passions de l'âme (1649) de Descartes, luego continuadas por Marin Mersenne, que confluyen con la tradición de la denominada "música poética", la teoría de los afectos (Affektenlehre) y las famosas equivalencias de Charpentier, Mattheson y Rameau de tonalidades musicales y afectos concretos. ${ }^{40}$

La aplicación ad hoc de estas teorías a la ópera está muy marcada por la forma en que se ha interpretado su nacimiento. En el octavo capítulo de su Italian Opera, David R. B. Kimbell sostiene que, desde Monteverdi, "la expresión convincente y conmovedora de las afecciones hubo de ser la tarea principal del compositor de ópera". ${ }^{41}$ John Bokina llega a mantener, desde una postura idealista, que "la ópera barroca temprana en su conjunto fue la culminación de la especulación del Renacimiento sobre el poder retórico de la música", algo que justifica desde un formalismo temático, al sostener que "de todas las artes, la música fue la más apta tanto para representar como para despertar las pasiones o los afectos". ${ }^{42}$ También Heinrich F. Plett, en el capítulo sobre música en

puede provenir de nuestros primeros recuerdos de comunicación compartida con nuestros cuidadores. En lugar de alimentar la ansiedad, estos sonidos tal vez sean el recuerdo de un entorno educativo". ("Our pleasure in opera's melismatic fragmentation or occlusion of the word may stem from our earliest memories of shared communication with our carers. Rather than fuelling anxiety, these sounds perhaps recall a nurturing environment") (Rutherford, "Voices and Singers", I23).

39. Les caractères de M. de La Bruyère, I (Ámsterdam: Pierre Hiccar, 1756), I26-I27. La definición aparece, con la cita a La Bruyère, en la voz "Opera" de la Encyclopedie, ou Dictionnaire raisonné des sciences, des arts et des métiers, XI (Neuchatel: Samuel Faulchese \& Compagnie, I765), 494.

40. Véase Rubén López Cano, Música y retórica en el barroco (Ciudad de México: Universidad Nacional Autónoma de México, 2000).

4I. David R.B. Kimbell, Italian Opera (Cambridge: Cambridge University Press, 1995), I40.

42. John Bokina, Opera and Politics: From Monteverdi to Henze (New Haven y Londres: Yale University Press, 1997), 22. 
Rethoric and Renaissance Culture, supone que "el rasgo común más evidente que comparten la música y la retórica es su pretendida eficacia”, y pone como ejemplo las óperas de Monteverdi. ${ }^{43}$

Por último, podemos destacar los enfoques "vocalistas", que convierten la ópera en una plataforma para la voz o el canto. Lo esencial de la ópera serían los cantantes, una idea vinculada al tema de Orfeo que, en el fondo, tampoco se comprende sin la apoteosis de Monteverdi como compositor genial. Baste un ejemplo de Operatic Afterlives (20II) de Michal Grover-Friedlander:

Este libro sigue las implicaciones más extremas que implica la ópera, fundada como está en el mito de Orfeo: un intento por revivir a los muertos con el poder otorgado al canto. El curso de la historia de la ópera está determinado por manifestaciones estilísticas sobre el poder del canto en lirismo, virtuosismo, fuerza dramática, sincronización con el texto, etc. El legado órfico de la ópera se encuentra en casi todos los aspectos del canto, empezando por el hecho mismo de que el canto es el modo de expresión del personaje. Si los personajes son la fuente y el origen de sus expresiones, si la canción surge de ellos (que es como concebimos el pensamiento y la conversación de las personas dramáticas), entonces todos ellos hablan y piensan en canciones. [...] Los personajes operísticos son todos descendientes de Orfeo. ${ }^{44}$

43. Heinrich F. Plett, Rhetoric and Renaissance Culture (Berlín y Nueva York: Walter de Gruyter, 2004): "Thus music claims to be able both to soothe and stir affections in the human soul. Perhaps the most famous musical expression of a passion is the Lamento of Arianna which has survived as the only musical piece from an opera of the same title now lost. At its performance in 1607 , the audience is reported to have been moved to tears; so strong evidently was its emotional potential that it engendered an overwhelming effect" (373).

44. "This book follows the most extreme implications of what opera entails, founded as it is on the myth of Orpheus: an attempt to revive the dead with the power granted to singing. The course of the history of opera is determined according to stylistic manifestations of the power of singing in lyricism, virtuosity, dramatic force, synchronization with text, etc. Opera's Orphic legacy is located in almost all aspects of singing, starting from the very fact that singing is its character's mode of utterance. If characters are the source and origin of their utterances, if song stems from them (which is how we conceive of the dramatic personae's thinking and conversing), then they all speak and think in songs. [...] Operatic characters are all descendents of Orpheus", en Michal Grover-Friedlander, Operatic Afterlives (Nueva York: Zone Books, 20II), I3-I4. La autora aclara sus influencias más adelante, y remarca que lo esencial de la ópera es la voz: "Sigo a Abbate, Cavell, Starobinski, Poizat y otros en la posición de la voz cantante por encima de todos los demás componentes como lo esencial en la ópera". "I join Abbate, Cavell, Starobinski, Poizat, and others in positioning the singing voice above all other constituents as 


\section{DOI: https://doi.org/10.22201/iie.18703062e.2021.119.2765}

382

DANIEL MARTÍN SÁEZ

Como se ha visto, estos subtipos pueden combinarse para comprender los presupuestos filosóficos fundamentales de un autor. Por ejemplo, la visión de Castarède, basada en la voz materna, tiene elementos "psicologistas" y "vocalistas", estando los segundos subordinados a los primeros.

\section{Las ideas ontológicas de ópera}

Las visiones "ontológicas", tal como las entenderemos aquí, hacen hincapié en realidades teóricamente interobjetuales (como "mundo" o "naturaleza"), donde los sujetos quedan hasta cierto punto emborronados, subordinados a ese universo de objetos que se limitan a reproducir de forma pasiva. Desde este enfoque, la ópera sería entendida precisamente en tanto que parte de ese mundo, comprendido como una totalidad dinámica, pero también fija, ahistórica y, por tanto, sincrónica. El mejor ejemplo de esta postura lo encontramos en Die Welt als Wille und Vorstellung (I819-1859) de Arthur Schopenhauer, ${ }^{45}$ cuya influencia sobre Wagner es conocida. ${ }^{46}$ Desde la metafísica musical del alemán (heredera de ideas previas, como la cosmología pitagórica, la episteme platónica, la música del quadrivium y la "matemática inconsciente" leibniziana), la ópera se presenta como una "inversión" del verdadero papel ontológico de la "música" (entendida como sónica, no-lingüística), pues la Wille desbordaría por completo el lenguaje. La única ópera "auténtica" es aquella que se entrega a la música, entendida como "una objetivación y un trasunto tan inmediato de la íntegra voluntad como lo es el mundo mismo", y establece así "una analogía entre la música y las ideas, cuya manifestación en la pluralidad e imperfección es el mundo visible". De esta manera entiende Schopenhauer las óperas de Gioachino Rossini, cuya música habla "tan clara y puramente su propio lenguaje" que "no precisa de las palabras y por eso también surte todo su efecto al ser interpretada con sim-

what is essential to opera" (I6). Otras influencias citadas más adelante son Gary Tomlinson y Slavoj Žižek.

45. Aunque estaríamos tentados a situar su ontología como un espiritualismo, dado el antropomorfismo aparente de la idea de "voluntad", la Wille del alemán se asemeja más a una fuerza cósmica interobjetual, que desborda a los sujetos en tanto que "racionales", etc., para comprenderlos como naturales, cósmicos, movidos por fuerzas "inconscientes”, etc., cuyo sentido último es aplicable tanto a lo biológico como a lo físico o lo químico.

46. Véase Milton E. Brener, Wagner and Schopenhauer. A Closer Look (Nueva York: Xlibris, 20I4). 
ples instrumentos orquestales". ${ }^{47}$ Una interpretación similar parece esbozarse en Kierkegaard, cuando propone cerrar los ojos para escuchar Don Giovanni..$^{8}$

Esto puede parecer algo superado en el presente, pero no lo es. El formalismo musical, desde Eduard Hanslick en adelante, mantuvo esta postura sobre la ópera después de Schopenhauer, ${ }^{49}$ y el filósofo americano de la música más influyente de las últimas décadas, Peter Kivy (1934-20I7), siempre mantuvo que la ópera sólo podía ser un arte auténtico en términos musicales, debido a un supuesto "problema" de la música para expresar cualquier tipo de contenido lingüístico. Kivy llega a esta conclusión desde una posición formalista híbrido-caótica de la ópera cuyos fundamentos descansan en esta tradición ontológica, ligada a la idea (acuñada por Wagner) de "música absoluta" so Por repetir dos de sus ejemplos: la realización de la idea de ópera como dramma per musica haría que uno se aburriera escuchando a Monteverdi, mientras que las óperas de Mozart producirían un evidente placer estético por sus cualidades sinfónicas, instrumentales. ${ }^{\text {II }}$

\section{Las ideas superestructurales de ópera}

El concepto central de las visiones superestructurales es el de "sociedad", en la que un grupo consigue imponerse a los demás, al funcionar como infraestructura que reproduce las superestructuras necesarias para mantenerse, entre las cuales estaría la ópera, que se entendería como un mero reflejo de esa infraestructura. Según se comprenda esa sociedad como organizada por clases (burgueses y proletarios, etc.) o según formas políticas abstractas (monarquía, aristocracia, república, democracia, etc.), tendremos dos formas distinguibles

47. Arthur Schopenhauer, El mundo como voluntad y representación, I, Roberto R. Aramayo, ed. (Madrid: Fondo de Cultura Económica, 2003), 35I-355.

48. Daniel Martín Sáez, "Kierkegaard y Mozart. La muerte a través de Don Giovanni”, en José María Carabante y Antonio Lastra, eds., El Libro de Kierkegaard. Estudios en el segundo centenario de su nacimiento (I8I3-2013) (Valencia: Nexofía, 2013), 76-92.

49. Véase Marianne Betz, "Opera Composition and Cultural Environment", en Greenwald, The Oxford Handbook of Opera, 632.

50. Véase Carl Dahlhaus, La idea de la música absoluta, trad. Ramón Barce Benito (Barcelona: Idea Books, 1999).

5I. Daniel Martín Sáez, "La idea de ópera de Peter Kivy. El caballo de Troya del formalismo", en José Antônio Baeta Zille, ed., Diálogos com o Som, vol. V (Minas Gerais: Escola de Música de la Universidade Estadual, 2019), 22I-246. 


\section{DOI: https://doi.org/10.22201/iie.18703062e.2021.119.2765}

384

DANIEL MARTÍN SÁEZ

de entender la ópera: una "sociologista" y otra "politologista", al funcionar la dicotomía sujeto/objeto desde la distinción entre la sociedad (realidad intersubjetual) y la ópera (objeto), y al acudir para ello a la metáfora del reflejo (la ópera refleja a la sociedad o al poder).

Entre las ideas sociologistas destacan, por sus pretensiones filosóficas, algunas ideas de T. W. Adorno. En el capítulo "Ópera" de su Dissonanzen (1968), interpreta la hipotética "crisis de la ópera" del siglo xx, refiriéndose al contraste entre "un público maltratado económicamente" y los "onerosos costes de producción" del género. Adorno define la ópera desde la sociedad, definida en este caso como una "sociedad de masas" marcada por las tecnologías y el realismo del cine, que haría "insoportables las personas que cantan como si fuese algo natural", pero también el "privilegio cultural" operístico, su "glorificación del individuo" y "todo lo que de modo inverosímil se finge en cada ópera". Sus ideas derivan así en el enfoque híbrido-caótico, lo que explica su cercanía a la posición de Schopenhauer: las únicas óperas posibles en el siglo xx son aquellas que, como las obras de Schoenberg, se oponen a "las tradicionales obligaciones de una opulenta tarde de teatro", y producen "la victoria de la composición sobre la ópera". Así ocurriría en las óperas de Alban Berg, como Wozzeck, cuya calidad se explicaría por "una estructura compositiva autónoma, ajena por completo al drama musical precedente", o Lulú, cuya "música trasciende también aquí el género al que pretende complacer". ${ }^{52} \mathrm{Al}$ enfoque híbrido-caótico se opone, como ideal, el abandono de la ópera como género, que se lograría transformándola en música. Otras ideas sociologistas se pueden encontrar en la Historia social de la ópera de Daniel Snowman, para quien "el código más apropiado respecto a la forma de vestir, el precio de una localidad, el comportamiento de otros miembros integrantes de la audiencia, la supuesta omnicompetencia de un acosado gerente, la amenaza de acciones legales... todo ello forma parte de la historia de la ópera". ${ }^{33} \mathrm{Si}$ se considera que esto es lo esencial y puede explicar la "historia" operística, estaríamos ante un sociologismo.

52. Theodor W. Adorno, Disonancias. Introducción a la sociología de la música, trad. Gabriel Menéndez Torrellas (Madrid: Akal, 2009), 256-26I. Sobre las ideas de Adorno en torno a la ópera véase Daniel Martín Sáez, "La crisis de la ópera en la obra de Theodor Adorno. Historia y crítica de un tópico infundado", Opus. Revista da Associação Nacional de Pesquisa e Pós-Graduação em Música 27, núm. I (202I), I-I9.

53. Daniel Snowman, Historia social de la ópera, trad. Ernesto Junquera (Madrid: Siruela, 2012), 123. 


\section{DOI: https://doi.org/10.22201/iie.18703062e.2021.119.2765}

¿QUÉ ES LA ÓPERA? UNA TIPOLOGÍA GENERAL

El enfoque "politologista" podemos encontrarlo en obras como Opera and Politics: From Monteverdi to Henze (1997) de John Bokina, que acude a la metáfora del "reflejo":

Desde su origen en las cortes aristocráticas de Italia, la ópera ha sido un arte eminentemente político. Ha reflejado, en formas complejas y mediadas, a los personajes y acontecimientos políticos significativos que han conformado al mundo occidental moderno: reyes y golpes de Estado, clases y conflictos de clase, rebeliones y revoluciones. Al retratar a la política en este nivel macro, la ópera ha abordado muchos de los temas característicos del pensamiento político moderno y contemporáneo: la monarquía y el republicanismo; las relaciones entre clases, estados y géneros; la revolución y la utopía; y las funciones del arte y el artista en una sociedad cada vez más compleja. ${ }^{54}$

Ruth Bereson, en The Operatic State. Cultural Policiy and the Opera House (2002), ha mantenido que "la ópera ha desempeñado la función de legitimar el poder del Estado por medio del uso de rituales ceremoniales desde sus inicios", y establece tal conexión entre la ópera y algunas formas políticas que llega a identificarlas, al entender ciertos rituales monárquicos como operísticos: "el papel ritual que la monarquía británica desempeña con sus carruajes, uniformes, palacios, ceremonias y joyas" es, para nuestra autora, "operístico". ${ }^{5}$ Mitchell Cohen, profesor de Ciencia Política en el Baruch College en el Graduate Center of the City University of New York, ha caído en posiciones similares en The Politics of Opera: A History from Monteverdi to Mozart (2017). El politólogo, como todos los anteriores, utiliza una idea de política marcada por la división secularizadora entre política y religión, lo que explica que desatiendan por completo los Estados Pontificios, uno de los más importantes de Europa

54. "From the time of its origin in the aristocratic courts of Italy, opera has been an eminently political art. It has reflected, in complex and mediated forms, the significant political personages and events that have shaped the modern Western world: kings and coups, classes and class conflict, rebels and revolutions. As it portrayed politics at this macro level, opera has addressed many of the characteristic themes of modern and contemporary political thought: monarchy and republicanism; the relations between classes, statuses, and genders; revolution and utopia; and the roles of art and the artist within an increasingly complex society", en Bokina, Opera and Politics, 2.

55. Ruth Bereson, The Operatic State. Cultural Policy and the Opera House (Londres y Nueva York: Routledge, 2002), 3-4. 


\section{DOI: https://doi.org/10.22201/iie.18703062e.2021.119.2765}

en el siglo XviI. ${ }^{56}$ Por la misma razón, Cohen olvida el caso crucial de la Mancomunidad de Polonia-Lituania, tan vinculada al catolicismo en estos años. ${ }^{57}$

Una deriva de este enfoque político es el enfoque "republicanista", que podemos encontrar en autores como Gerard Mortier, para quien "los primeros grandes éxitos del género operístico se producen en ciudades republicanas, urbes mercantiles como Venecia y Hamburgo, y se dirigen a ciudadanos", marcando así la historia del género. ${ }^{58}$

\section{Las ideas románticas de ópera}

La idea de "obra" es la clave de las visiones románticas, cuyo modelo no es un conjunto de parámetros formales, sino más bien un género previo o futuro conformado por obras ideales, cuya objetualidad sólo se puede explicar en términos históricos. Distingo dos enfoques: el "nostálgico", según el cual la ópera ha de seguir un tipo de obra ideal existente en el pasado, y el "alquímico", que se refiere más bien a un proyecto futuro, para el cual sólo se empiezan a dar las condiciones históricas en el presente más inmediato del compositor.

El enfoque "nostálgico" puede ser negativo o positivo, según se considere que la ópera consigue o no asemejarse a su modelo antiguo. El "positivo" aparece del modo más claro en el primer gran diccionario musical de la historia, el famoso A Dictionary of Music and Musicians de George Grove, donde el modelo de la ópera es el teatro griego, de hecho, denominado ya como "ópera":

OPERA. (Italiano: Opera, abreviación de Opera in Musica, una 'Obra Musical', Drama per la Musica; Francés: Opéra; Alemán: Oper, Singspiel). Un drama, trágico o cómico, totalmente cantado, con una adecuada escenografía y acción, con acompańamiento de una orquesta completa.

Puede parecer extraño hablar de la ópera como una de las instituciones más antiguas que existen; sin embargo, la búsqueda de su origen nos lleva de vuelta a

56. Mitchell Cohen, The Politics of Opera: A History from Monteverdi to Mozart (Princeton y Oxford: Princeton University Press, 2020).

57. Daniel Martín Sáez, "Ópera y diplomacia entre Italia y Polonia: del paso de Vladislao Vasa por Florencia hasta la inauguración del teatro de Varsovia", en Iskrena Yordanova y Francesco Cotticelli, eds., Diplomacy and Aristocracy as Patrons of Music and Theatre in Europe of the Ancien Régime (Viena: Hollitzer Verlag, 2019), 37-62.

58. Gerard Mortier, Dramaturgia de una pasión (Madrid: Akal, 2010), I2-I3. 


\section{DOI: https://doi.org/10.22201/iie.18703062e.2021.119.2765}

¿QUÉ ES LA ÓPERA? UNA TIPOLOGÍA GENERAL

un tiempo muy anterior al comienzo de la Era Cristiana; de hecho, debemos obtener sus detalles de la Historia de la Grecia Antigua, ya que es tan antigua como el propio Drama. Fue criada en Atenas, en ese glorioso Teatro cuyas propiedades acústicas nunca han sido igualadas. Sus primeros libretistas fueron Esquilo y Sófocles; y su primera orquesta, una banda de liras y flautas. No hay duda de esto. ${ }^{9}$

Esta idea, que hoy puede sonar desfasada, aún se puede encontrar en obras relativamente recientes como An Invitation to the Opera, de John Louis DiGaetani:

La historia de la ópera comienza con una de las fuentes más antiguas de la civilización occidental: la cultura de la antigua Grecia. Uno de los regalos más duraderos e impresionantes de los antiguos griegos a nuestra cultura es el drama en forma de tragedia. Las obras de Esquilo, Sófocles y Eurípides siguen siendo los fundamentos del teatro en Occidente. De ese rico campo de la tragedia griega temprana creció la forma de arte que llamamos ópera. ${ }^{60}$

El enfoque nostálgico "negativo" considera la ópera como una "caricatura” del teatro griego, y ha sido aún más influyente. Tomaré como paradigma de este enfoque la idea expuesta por Friedrich Schelling en su Philosophie der Kunst:

Quiero observar aún que la composición más perfecta de todas las artes, la reunión de poesía y pintura por la danza, es sintetizada a su vez en la manifestación teatral más compleja que fue el drama en la antigüedad, de la que sólo nos ha quedado una caricatura, la ópera, que, con un estilo más elevado y noble por parte de la poesía así como de las demás artes concurrentes, podría conducirnos de nuevo a la representación del antiguo drama combinado con música y canto. ${ }^{61}$

59. George Grove, A Dictionary of Music and Musicians, by Eminent Writers, English and Foreign, with Illustrations and Woodcuts, vol. 2 (Londres: MacMillan and Co., I880), 497.

6o. "Opera's history begins with one of the most ancient sources of Western civilization, the culture of ancient Greece. One of the most enduring and impressive gifts of the ancient Greeks to our culture is drama in the form of tragedy. The plays of Aeschylus, Sophocles, and Euripides remain the foundations of theater in the West. From that rich field of early Greek tragedy grew the art form we call opera", en John Louis DiGaetani, An Invitation to the Opera (Nueva York y Oxford: Facts on File Publications, 1986), I3.

6I. Friedrich Schelling, Filosofía del arte, trad. Virginia López-Domínguez (Madrid: Tecnos, 1999), 492. 


\section{DOI: https://doi.org/10.22201/iie.18703062e.2021.119.2765}

388

DANIEL MARTÍN SÁEZ

Schelling mantiene cierto formalismo en la consideración de una y otra obra, tomando la ópera como un género híbrido-caótico, frente al teatro griego, que sería híbrido-armónico, pero el criterio de la distinción es esencialmente histórico. Esta visión es mucho más importante y recurrente de lo que parece. Unas siete décadas después, Nietzsche acude a la misma metáfora para entender la ópera, por oposición a la tragedia griega, cuya esencia sólo podríamos conocer en las siguientes condiciones:

cuando alguna vez, en una hora intensa y rica de fantasía, hacemos desfilar ante nuestra alma la ópera de un modo tan idealizado, que se nos da precisamente una intuición del drama musical antiguo. Pues por muy desfiguradas que se encuentren todas las proporciones en la denominada gran ópera, aun cuando ésta sea producto de la dispersión, no del recogimiento, esclava de la peor de las versificaciones y de una música indigna [...] no hay, con todo, ningún otro medio de hacerse una idea clara sobre Sófocles más que intentando adivinar, a partir de esa caricatura, su imagen primordial, y eliminando con el pensamiento, en una hora de entusiasmo, todo lo torcido y desfigurado. ${ }^{62}$

La conexión con las teorías híbrido-caóticas, propias del siglo XviII, es obvia incluso en términos históricos. Un precedente de esta definición, todavía no romántico, se puede observar en la primera parte de la Dissertation sur la Tragedie Ancienne et Moderne de Voltaire, dedicada a "Las tragedias griegas imitadas por algunas óperas italianas y francesas" en el cual compara la ópera y la tragedia para destacar la superioridad de la segunda, hasta el punto de afirmar que "la ópera, seduciendo a los italianos con los placeres de la música, destruyó la verdadera tragedia griega que había hecho renacer". ${ }^{63}$

El enfoque "alquímico", por el contrario, sitúa esa obra ideal en el futuro. De nuevo, Wagner y el joven Nietzsche cobran especial protagonismo, pero no para definir la "ópera" como género realmente existente, sino para defender un nuevo proyecto melodramático, derivado de facto de la ópera, pero de dicto distinto e incluso opuesto, denominado "drama". El drama, entendido como "obra de arte total" (Gesamtkunstwerk), supone una visión alquímica donde no sólo se funden todas las artes, como comúnmente se repite, sino también todas

62. Friedrich Nietzsche, "El drama musical griego", en El nacimiento de la tragedia, trad. Andrés Sánchez Pascual (Madrid: Alianza, 2010), 207-208.

63. Oeuvres completes de Voltaire, t. III (París: Antoine-Augustin Renouard, I819), 472-473. 
las facultades humanas y los saberes imaginables, e incluso todas las contradicciones sociales. El drama aparece como una especie de microcosmos, nutrido no sólo por las artes del presente, sino también de alguna forma por las artes del pasado, junto a otros saberes científicos, religiosos e históricos. No se trata sólo de una fusión de artes, sino también de una fusión de épocas y saberes, plasmados en esas "obras totales" de Wagner. Es interesante constatar cómo continúa funcionando, en un segundo plano, el subtipo nostálgico. En La obra de arte del futuro, la danza, la música y la poesía aparecen como "tres encantadoras hermanas helénicas" que han de unirse "concertando sus miembros y sus pechos en un apasionado beso de amor" ${ }^{64} \mathrm{La}$ alquimia resultante puede observarse en el siguiente pasaje: "La gran obra de arte integral [grosse Gesamtkunstwerk], que ha de abarcar todos los géneros del arte utilizando en cierto modo como medio a cada uno e incluso aniquilándolos en aras de la consecución de la finalidad global de todos ellos." ${ }_{5}$

Nietzsche profundiza en esta idea en "Richard Wagner en Bayreuth". La ópera se comprende, como hemos visto, desde una visión nostálgica negativa, que llevaría precisamente a la necesidad de un nuevo género, capaz de culminar el verdadero impulso de la ópera:

Todas las artes modernas que ha habido hasta ahora, bien sea en cuanto artes solitarias y atrofiadas o en cuanto artes determinadas por el lujo, con la existencia de dicha empresa han perdido la mitad de su valor; incluso los vacilantes y mal conjuntados recuerdos de un arte verdadero que nosotros los modernos teníamos en nuestra memoria gracias a los griegos, desde este momento deben quedar en suspenso mientras no sean capaces de brillar ahora ellos mismos a la luz de una nueva comprensión [...] nosotros, los discípulos del arte resucitado.

Pero esa unión es futura, suponiendo una unión de saberes, poesía, historia, mitología, que confluyen en la propia figura de Wagner:

El innovador del drama simple, el descubridor de la posición de las artes en la verdadera sociedad humana, el poetizante intérprete de pretéritas formas de considerar la vida, el filósofo, el historiador, el esteta y crítico Wagner, el maestro del lenguaje,

64. Richard Wagner, La obra de arte del futuro, trad. Joan B. Llinares y Francisco López (Valencia: PUV, 2007), 59 .

65. Wagner, La obra de arte del futuro, 47. 


\section{DOI: https://doi.org/10.22201/iie.18703062e.2021.119.2765}

el mitólogo y mitopoeta que por vez primera acabó de forjar un anillo que abrazó un todo magnífico, antiquísimo, tremendo conjunto, en el cual dejó grabadas las runas de su espíritu — iqué caudal de saber tuvo que reunir y abarcar Wagner para poder convertirse en todo esto! ${ }^{66}$

El carácter objetualista se observa en que todo ello se encarna en una "obra" mediante un proceso de simplificación:

Wagner [...] agarra y reúne lo que estaba aislado, debilitado y abandonado, tiene, si está permitida una expresión médica, una fuerza astringente: en este sentido pertenece a las más grandes potencias culturales. Impera sobre las artes, las religiones, las diferentes historias de los pueblos y, no obstante, es la antítesis de un polígrafo, de un espíritu que solamente recopila y ordena: porque es un escultor que sintetiza en una única imagen y le da vida a lo que ha unificado, con lo cual es un simplificador del mundo. ${ }^{67}$

Esta postura no se puede entender como una visión híbrido-armónica, pues incluye la dimensión diacrónica y, por tanto, desborda el formalismo. El tema de la "unión de todas las artes", en un sentido híbrido-formalista, se puede encontrar en la Filosofía de lo bello de Eduard von Hartmann, donde predomina la idea de forma sobre la idea de obra en sentido romántico. ${ }^{68}$

66. Nietzsche, "Richard Wagner en Bayreuth", 99.

67. Nietzsche, "Richard Wagner en Bayreuth", I05.

68. "Entre las formas de unión que pueden darse entre la poesía y las artes perceptivas sólo existe una que reúna cuatro componentes: la ópera, en la que se unen la poesía, la gesticulación propia del canto, la música instrumental la pintura de decorados. [...] Cuando la ópera logra alcanzar un adecuado equilibrio entre sus cuatro componentes, consiguiendo unir orgánicamente las artes que en ella se encuentran implicadas, ocupa el puesto más elevado dentro de las artes compuestas. Al incluir la poesía y las tres artes perceptivas, esta unión cuaternaria de los principales géneros de las artes libres se presenta, en sentido completo y eminente, como la obra de arte total, mientras que, en comparación con ella, las uniones ternarias y binarias aparecen únicamente como obras totales de arte incompletas o unilaterales", en Eduard von Hartmann, Filosofía de lo bello. Una reflexión sobre lo inconsciente en el arte, trad. Manuel Pérez Cornejo (Valencia: PUV, 200I), 367-37I. 


\section{Las ideas gremiales de ópera}

Denomino visiones gremiales a aquellas cuyo soporte último depende de disciplinas positivas, asentadas institucionalmente, a partir de ideas que se consideran metafísicas por depender de la clasificación estética de las artes. Entre ellas se pueden contar las diversas historias (de la literatura, del teatro, etc.), aunque las más destacables son la musicología, las denominadas ciencias del espectáculo y los opera studies, cuyo fundamento ha sido en todos los casos la demarcación de un "objeto histórico" de estudio, según una idea de música, de literatura, de teatro, de espectáculo o de ópera que ha dependido en última instancia de ideas esteticistas, confiando en que es posible cerrar un campo para cada uno de esos objetos, como si realmente existiera la música, la literatura, etc., algo que justamente la ópera contribuye a poner en duda.

Me limito aquí a considerar como defensor de una visión "musicologista" a Peter Kivy, para quien el objeto "música" es tan evidente, como hemos visto, que lo opone al objeto "literatura", casi como dos piezas de un rompecabezas que no encajan entre sí. Para Kivy, lo esencial de la ópera, cuando es valiosa estéticamente, es la música, y, por tanto, la ópera ha de considerarse con propiedad como un género musical. Por el contrario, el enfoque "literario" ha estado muy extendido entre quienes han mantenido una visión híbrido-caótica de la ópera, como Voltaire, pero también Crescimbeni, Ludovico Antonio Muratori, Pier Jacopo Martello, Francesco Saverio Quadrio, Girolamo Tiraboschi o Francesco Algarotti. Lo esencial de la ópera en este caso sería su carácter literario, al que la música y el resto de las artes deberían subordinarse. El propio Wagner parece mantener en ocasiones una idea parecida, al subordinar la música al drama, como hace Joseph Kerman en Opera as Drama. Al llevar este enfoque a su extremo, Kerman se permite criticar, por ejemplo, las óperas órficas de Monteverdi y Gluck porque, en su opinión, fracasan en acoger la catástrofe final implícita en la leyenda de Orfeo, ${ }^{69} \mathrm{y}$ desatienden por completo otras razones (no sólo estéticas, sino también políticas, académicas, etc.) que pudieran estar en la base de dicha decisión.

Más interesante, por su relativa novedad, es el enfoque "espectacular", que entendería la ópera como un subgénero dentro de la "historia del espectáculo”. En su Dèi, Semidei, Uomini, Sara Mamone, profesora en la Universidad de

69. Joseph Kerman, Opera as Drama. New and Revised Edition (Berkeley: University of California Press, 1988), 16-25. 


\section{DOI: https://doi.org/10.22201/iie.18703062e.2021.119.2765}

Florencia de Historia del Teatro y del Espectáculo, presenta esta "historia del espectáculo" como una "nueva disciplina", cuyos precedentes se pueden remontar a Emile Mâle a principios del siglo xx, que cristalizan a mediados de siglo en las obras de Oskar Fischel, George R. Kernodle, Pierre Francastel, Heinz Kindermann y Ludovico Zorzi, entre otros. Mamone reconoce que estos autores subordinaban la idea de espectáculo a la idea de "arte", y propone una nueva fundación de la disciplina, que tenga en cuenta múltiples tipos de objeto, desde lienzos, trajes, edificios teatrales y coreografías hasta partituras, textos, autores, públicos y testimonios escritos, en cuyas relaciones surgiría un "objeto" que no es tal, sino inventado por el investigador, que se denominará "espectáculo" y que sería en realidad un "objeto mental". Desde una perspectiva estética, se trata de una idea interdisciplinar, aunque la autora no renuncia del todo a la idea "objetual" que, tras la reconstrucción a partir de las fuentes, remite a categorías estéticas, precisamente para que ese objeto pueda ser un "espectáculo", que define como "aquel conjunto complejo de fenómenos relativos a la representación". ${ }^{\circ}$ No sería errado entender esta disciplina como un intento por comprender fenómenos históricos que, como la ópera, no encajan nada bien con las categorías estéticas, algo que también está en sintonía con las críticas realizadas desde la denominada "nueva musicología" a las categorías de la musicología como disciplina positiva, incluso "científica", tal como fue concebida a finales del siglo XIx. Lo esencial de la ópera, desde esta perspectiva, sería su condición de "espectáculo", que nos ofrecería así una visión gremial concreta, con sus propias preferencias positivas respecto a la forma de tratar la ópera.

El último paso en esta búsqueda sólo podía ser una disciplina que tomase, directamente, el nombre de su objeto, sin arriesgarse a tildarlo con cualquier categoría abstracta (ya sea música, literatura, espectáculo o cualquier otra). La ópera será estudiada por unos hipotéticos "estudios operísticos" (opera studies). Esta postura, que toma su nombre de los estudios culturales, no ofrece ningún criterio particular para comprender la ópera y, por eso mismo, difícilmente puede analizarse, pero hasta la fecha no parece ser más que un "cajón de sastre" donde tienen cabida todas aquellas reflexiones que no encuentran su espacio en otros gremios. Más que un enfoque interdisciplinar, se trata de un enfoque adisciplinar.

70. Sara Mamone, Dèi, Semidei, Uomini (Roma: Bulzoni, 2003), 29-33. 


\section{Las ideas espiritualistas}

Como hemos visto, algunas ideas derivadas del formalismo híbrido-caótico, en su sentido positivo, derivaban en un formalismo temático que convertía la ópera en una expresión adecuada de la vida. Algo así podemos observar en Romain Rolland, uno de los padres de la historiografía operística en Francia, que define la ópera desde una mirada que podríamos denominar "vitalista":

Extraordinaria obra de arte que se esfuerza por plasmar, no sólo la apariencia poética de la vida, sino la vida misma, el hombre completo, el árbol con sus raíces, el mundo de las pasiones y los sentimientos oscuros — no como la razón los encuentra y clasifica, desecados por el análisis_ - sino vivos, palpitantes, en el corazón mismo de la acción..$^{71}$

También espiritualista parece El canto metafísico (1999) de Gary Tomlinson, profesor en la Universidad de Yale y uno de los estudiosos más reputados del presente sobre música del siglo Xvir. En esta obra, Tomlinson parte de un enfoque subjetual vocalista, y sostiene que "las funciones de la voz operística" de cada época manifiestan "las concepciones contemporáneas del sujeto humano" y ponen a sus oyentes "en contacto con mundos invisibles y suprasensoriales". Este enfoque "metafísico" tiene consecuencias sobre el género al que pertenece la ópera. Tomlinson la define como "una subespecie dentro de una enorme familia de experiencias humanas surgidas de la exaltación de la emisión vocal — salmodia, grito, canto, ensalmo, etc.". La función de la ópera sería dar "voz a una ordenación del mundo que incluya terrenos invisibles", lo que denomina "reinos ocultos", "mundos ocultos" o "realidades suprasensibles", que no se entienden al modo ontológico de Schopenhauer, sino como "constructos culturales" que "reflejan los modos más profundos en los que una cultura señala en el mundo su ubicación y la de los individuos que la constituyen". ${ }^{2}$

7I. “Oeuvre d'art extraordinaire qui s'efforce de rendre, non seulement l'apparence poétique de la vie, mais la vie elle même, l'homme tout entier, l'arbre avec ses racines, le monde des passions et des sentiments obscurs, -non tels que la raison les retrouve et les classe, desséchés par l'analyse,- mais vivants, frémissants, au sein même de l'action”, en Romain Rolland, Les Origines du théâtre lyrique moderne: Histoire de l'opéra en Europe avant Lully et Scarlatti (París: Ernest Thorin, I895), 3.

72. Gary Tomlinson, El canto metafísico, trad. T. Paul Silles (Barcelona: Idea Books, 200I), 7-I2. 


\section{DOI: https://doi.org/10.22201/iie.18703062e.2021.119.2765}

394

DANIEL MARTÍN SÁEZ

\section{Las ideas localistas de ópera}

Por visiones "localistas" entenderemos aquellas que definen la ópera como parte de una "nación", históricamente ligada a un locus geográfico, que habría dado lugar a un tipo humano concreto, distinguible de otros tipos humanos en virtud de ese locus, ya sea por su lengua, sus costumbres, sus formas de gobierno o cualquier otro factor cultural. En términos históricos, tales diferencias pueden ser mutables y transferibles, o inmutables e intransferibles. En el primer caso, hablaremos de un nacionalismo particularista. En el segundo, de un nacionalismo populista, considerando la vinculación histórica de esta postura a la idea del "espíritu del pueblo" (Volksgeist), que no se entiende sin la idea de cultura como propia de cada pueblo y la idea de ese pueblo como único sujeto de la soberanía.

Los ejemplos de particularismos son inagotables. Ya desde los siglos XVII y XVIII, es común distinguir los tipos o estilos de música particulares de cada reino o nación. En la citada carta Sur les opéra (1684) de Saint-Évremond, éste se refiere ya a "la diferencia que encuentro entre la manera de cantar de los italianos y de los franceses", ${ }^{73}$ pero ninguna de ellas se identifica con un "espíritu popular". Lecerf y Raguenet, ambos franceses, discuten sobre la superioridad de la ópera italiana frente a la francesa sin que eso implique una toma de partido espiritualista: tratan de definir un estilo, propio de una tradición concreta, y averiguar si es mejor o peor que otro, a partir de criterios pretendidamente universales. Un francés puede estar dispuesto a importar un estilo de otra nación y hacerlo propio, como ocurre durante la querella de los bufones. Un ginebrino como Rousseau y un alemán como Grimm defienden la música italiana frente a la francesa, y reciben apoyo de franceses que se oponen a Rameau. Todos ellos apelan a motivos racionales, ilustrados, no a una nación espiritual. Como es sabido, el propio Rameau sufriría en carne propia la disputa sobre quién era superior, si él o Lully. En el mismo año de 1752, en su Ensayo de un método para tocar la flauta travesera, Quantz distingue tres estilos: el francés, el italiano y el alemán, y pone diversos ejemplos operísticos. Quantz considera que el estilo alemán está influido por el italiano y el francés, sin que eso suponga un obstáculo para el desarrollo de un arte valioso en su territorio. La grandeza del estilo alemán está precisamente en unir lo mejor de ambos estilos, al asimilarlos de manera directa a partir de sus tradiciones

73. Saint-Évremond, "Sur les opéra", 78. 
operísticas. Su incidencia sobre la superioridad del estilo alemán, frente a otras naciones, se puede considerar un precedente del nacionalismo populista posterior, pero aún no aparece ni la idea de pueblo, ni la idea de cultura, ni la idea de soberanía nacional.

Es interesante destacar que, aunque la querella de los bufones parecía obsoleta hacia 1773, cuando Gluck publica una carta en el Mercure de Fran$c e$ criticando las "ridículas diferencias" entre las músicas nacionales, ${ }^{74}$ dos años después el propio Gluck viviría su propia querella, al formarse dos bandos entre sus partidarios y los de Niccolò Piccinni. Que los partidarios de un alemán y un italiano se enfrentaran en París muestra hasta qué punto este nacionalismo no tenía aún, a finales de siglo, un componente populista. Esto cambiaría sustancialmente tras la revolución francesa y, sobre todo, tras la cristalización del nacionalismo alemán, que situaría los debates nacionales en un terreno nuevo.

El enfoque "populista" tuvo especial difusión en los territorios germanos durante el siglo xIx. Con la influencia del nacionalismo alemán, se empezará a creer que lo importante no son los estilos de cada nación, sino la nación misma, identificada con el pueblo. Ya no se trata de comparar dos o más estilos, que eventualmente podrían ser intercambiables, sino dos o más naciones, de las cuales deriva un estilo propio e intransferible. En sus Lecciones sobre la filosofía de la historia, Hegel se expresaba así en torno a Italia:

Los italianos espiritualizan lo sensible en el arte y viven alegres; su naturaleza es la alegría, el arte y la poesía. Todos los italianos tienen por naturaleza una melodía en su garganta. Son naturalezas improvisadoras que se derraman totalmente en el arte y en el goce bienaventurado. Con semejante naturaleza artística, el Estado ha de ser necesariamente un azar. ${ }^{75}$

Este tipo de ideas se utilizan a menudo para explicar por qué la ópera nació en Italia. Baste leer el siguiente pasaje de Ruth Berges en The Backgrounds and Traditions of Opera:

Italia no es sólo el país que dio origen a la ópera. Italia y su gente también se asocian de manera más natural y popular con la ópera. Nada podría haber perturbado

74. Véase Anacleto Ferrer Mas, ed., Rousseau: música y lenguaje (Valencia: PUv, 2010), 202.

75. Georg Wilhelm Friedrich Hegel, Lecciones sobre la filosofía de la historia, trad. José Gaos (Barcelona: Círculo de Lectores, 1996), 859. 


\title{
DOI: https://doi.org/10.22201/iie.18703062e.2021.119.2765
}

\author{
396 DANIEL MARTÍN SÁEZ
}

el desarrollo de la ópera, como la controversia de Puccini-Gluck en París o la batalla de Wagner contra la escuela romántica alemana opuesta. Aunque hubo conflictos de menor importancia, la ópera en Italia floreció imperturbable a lo largo de su propio curso, una fuerza unificadora que creó y mantuvo sus tradiciones únicas. Dado que el idioma italiano es como la música, una vez que se unió a la melodía y se convirtió en ópera, esta forma de expresión musical se hizo inmensamente popular, eclipsando todas las demás. La voz predominó mientras la orquesta permanecía en segundo plano.

En Italia la ópera pertenece a las masas. No se dirige a una élite o minoría cultural con mentalidad estética. Los italianos son un pueblo emotivo, impulsivo y fácilmente excitable que expresa su aprobación o crítica en el teatro sin inhibiciones. El juicio no es pronunciado por unos pocos elegidos sino que surge de las filas del pueblo. Los italianos exigen que la ópera despierte sus sentimientos, y desde la profundidad de sus emociones responden. ${ }^{76}$

También Wagner es un ejemplo paradigmático desde esta perspectiva, en lo que podemos considerar la modulación racista de esta lógica localista. Ya hemos visto su distinción entre ópera y drama, entendiendo la primera desde un enfoque formalista híbrido-caótico, pero ese caos de la ópera incluía también un componente racista (antisemita) ligado a ideas típicas de un nacionalismo populista, que no está claro que hayamos superado del todo. La aparición de realidades foráneas en las propias óperas (turcos, chinos, japoneses, etc.), son difícilmente comprensibles al margen de una visión de la ópera como género propio de unos pueblos frente a otros. Baste pensar en la producción de óperas donde aparecen personajes de origen africano, como Otello de Verdi, que en Estados Unidos han sido

76. "Italy is not only the country which gave birth to opera; Italy and its people are also most naturally and popularly associated with opera. Here nothing like the Puccini-Gluck controversy in Paris or Wagner's battle against the opposing German romantic school could have disturbed operatic development. Although there were conflicts of minor nature, opera in Italy flourished unperturbed along its own course, a unifying force creating and maintaining its unique traditions. Since the Italian language itself is like music, once it was welded to melody and grew into opera, this form of musical expression became immensely popular, overshadowing all others. The voice predominated while the orchestra remained secondary. / In Italy opera belongs to the masses. It does not cater to an aesthetic-minded cultural elite or minority. Italians are an emotional, impulsive and easily excited people who express their approval or criticism in the theatre without inhibitions. Judgment is not pronounced by a chosen few but arises from the ranks of the people. Italians demand that opera arouse their feelings, and from the depth of their emotions they respond", en Ruth Berges, The Backgrounds and Traditions of Opera (Londres: A. S. Barnes and Company, 1961 y 1970), 23. 


\section{DOI: https://doi.org/10.22201/iie.18703062e.2021.119.2765}

¿QUÉ ES LA ÓPERA? UNA TIPOLOGÍA GENERAL

representados durante décadas por cantantes caucásicos embetunados, en sintonía con un género ligado a la esclavitud como los minstrels. En el Met de Nueva York, esta práctica no cesó de hecho hasta 2015, y sólo en 2017 hemos podido ver a una pareja de afroamericanos representando una ópera como La Bohème.

\section{Conclusión y critica de los tipos ideales}

Esta tipología nos permite avanzar muy poco en el planteamiento de la pregunta por la ópera. En primer lugar, resulta obvio que el cuestionamiento mismo significará cosas muy distintas según se mantenga una u otra idea, dando lugar a respuestas diversas e incluso contradictorias entre sí. Este simple hecho ya hace necesaria la crítica. En segundo lugar, sin embargo, parece que todas estas ideas comparten un elemento genérico común, que es precisamente la distinción sujeto/objeto, hecho que considero de gran valor, si es cierto, como sostengo aquí, que no es posible presentar una definición, sistemática y explícitamente desarrollada, que escape a los criterios de clasificación escogidos.

Esto permite acotar la crítica a dos cuestiones básicas: primero, la equivocidad de las definiciones existentes, basadas en una pluralidad de ideas, que impide saber qué es exactamente lo que queremos definir; segundo, la simplicidad gnoseológica de las ideas de ópera, basada en la distinción sujeto/objeto, ya sea porque la ópera se define como objeto u obra, o porque se define como una realidad subjetual, o porque se acude a conexiones abstractas entre sujetos o entre objetos. A mi modo de ver, esto convierte todas las ideas de ópera existentes en ideas metafísicas, dado que los autores citados presuponen una idea de sujeto y objeto hipostasiados, desgajados de un modo u otro de los materiales históricos. Dicho negativamente, ninguno de los autores citados ha probado que exista $e l$ sujeto, ni $e l$ objeto, ni la sociedad, ni $e l$ mundo, ni la obra, ni el espíritu, ni $e l$ arte, ni la nación, que presuponen como realidades metafísicas.

Esto podría tener una consecuencia inesperada. Por su relevancia durante cuatro siglos y la pluralidad de ideas que se ha desarrollado en torno a ella, la pregunta por la ópera podría servir para cuestionar la distinción sujeto/objeto. Los propios materiales operísticos nos ayudarían a ver que el mundo nunca es $e l$ mundo, sino que es un mundo, como pueda ser el mundo del sujeto que lo percibe y lo transforma con sus instrumentos, y que tampoco es nunca el sujeto, sino un sujeto concreto, que a su vez es un sujeto social, que lo será por pertenecer a una sociedad concreta, etc., y todos ellos se modifican entre 


\section{DOI: https://doi.org/10.22201/iie.18703062e.2021.119.2765}

sí ontológicamente, de formas variadas y plurales, con ritmos diversos y difíciles de prever. Cuando las cosas se analizan en profundidad, todo tiene algo de sujeto, de objeto, de mundo, de nación, de arte, etc. El error fundamental de las ideas de ópera se podría resumir así: ninguna de ellas tiene suficientemente en cuenta la historia de la ópera. Incluso en las visiones diacrónicas, como hemos visto, se parte de objetos o sujetos metafísicos.

Puesto que estas ideas no nos ayudan a entender qué es la ópera, salvo de manera indirecta (en la medida en que han formado parte de la historia de la ópera), quizá la única solución factible sea comenzar por el principio, evitando en lo posible los prejuicios implícitos en esta tipología de ideas. En lugar de introducir la ópera ad hoc dentro de una de esas categorías, habríamos de tratar sus realidades concretas: sus partituras, sus libretos, sus teatros, sus descripciones, sus testimonios, sus fuentes e instituciones, que acaso nos permitan reconstruir la razón mínima de su desarrollo histórico, aunque no podamos aspirar a una definición perfecta.

No hemos de negar que esto, en gran medida, ha conformado el trabajo de los musicólogos de las últimas décadas, que han desbordado en ejercicio la idea ingenua de un género estético-musical, aunque justamente su cualidad de "musicólogos" se transforme con ello en un misterio (los musicólogos del presente, en efecto, son mucho más que músico-logos: son historiadores de la literatura, del teatro, de la política, etc.). Por mucho que avance ese trabajo, sin embargo, no podremos evitar que la ópera siga siendo una idea filosófica, ligada a nuestra idea de sujeto y objeto, de la sociedad y el mundo, de la Edad Antigua y la Edad Moderna, introduciéndonos así en cuestiones que ninguna disciplina positiva estará nunca en condiciones de resolver. La idea de ópera seguirá requiriendo, por tanto, el tratamiento de ideas filosóficas, desde la política hasta la metafísica, desde la idea del hombre hasta la idea del arte, pero todas estas ideas deberán ser necesariamente redefinidas.

N.B. Esta investigación fue posible gracias a un contrato como Personal Investigador en Formación (FPI) en el Departamento de Filosofía de la Universidad Autónoma de Madrid, cuyos resultados fueron presentados en mi tesis doctoral inédita, titulada: "El nacimiento de la ópera. La legitimidad musical de la Edad Moderna” (Madrid: Universidad Autónoma de Madrid, 20I8). 